\title{
Charles Darwin and Silicon
}

\author{
Stephen J. Clarson
}

Received: 11 July 2009 /Accepted: 4 October 2009/Published online: 6 November 2009

(C) Springer Science + Business Media B.V. 2009

\section{Introduction}

The year 2009 sees Mankind celebrating the 200th Anniversary of the birth of Charles Robert Darwin (February 12, 1809) and also the 150th Anniversary of the publication of On The Origin of Species by Means of Natural Selection (November 22, 1859) [1] (Fig. 1).

I will describe herein some of the ways that silicon science and silicon technology have played an important role in helping to explain and to confirm Darwin's scientific theory of natural selection for life on Earth and on its evolution with time.

To quote Professor Richard Dawkins

"On The Origin of Species must be high on any serious list of the most important and influential books ever written. On it's first publication in 1859, Thomas Henry Huxley exclaimed "How extremely stupid of me not to have thought of that." Charles Darwin's revolutionary idea is, indeed, an astoundingly simple one, especially when you measure it against the magnitude of what it explains - every fact that we know about life on Earth [2]."

and to quote the late Professor Ernst Mayr:

"Evolution does not provide us with a codified set of ethical norms such as the Ten Commandments. Yet evolution did give us a capacity for stretching beyond

\section{S. J. Clarson $(\square)$}

Department of Chemical and Materials Engineering,

University of Cincinnati,

Cincinnati, OH 45221, USA

e-mail: Stephen.Clarson@UC.Edu our individual needs to take those of the larger group into account. And an understanding of evolution can give us a worldview that serves as the basis for a sound ethical system - an ethical system that can maintain a healthy human society and provide for the future of a world preserved by the guardianship of $\operatorname{man}[3] "$.

2 The Celebration of the 200th Anniversary of the Birth of Charles Robert Darwin and the 150th Anniversary of the Publication of "On the Origin of Species Means of Natural Selection"

The world has seen the production of a variety of coins, notes and stamps that honour Charles Darwin (Fig. 2) and his scientific legacy. A selection of the those from England are shown in Fig. 3 and 4.

Indeed Charles Darwin had replaced that other giant of the Victorian age - Charles Dickens - on the Bank of England Ten Pound note back in 2001 (see Figs. 5, 6, and 7).

\section{Some Contributions of Silicon to Darwin's Scientific Legacy}

(i) On The Role of Silicates in the Origin of Life on Earth There have been many demonstrations of the formation of simple biomolecules under the prebiotic conditions that once existed on Earth. Having made various amino acids and nucleic acids, one must next find a mechanism that can explain how these and other functional biomolecules are then polymerised into 
ON

\section{THE ORIGIN OF SPECIES}

BY MEANS OF NATURAL. SELECTION,

on vats

PRESERVATION OF FAVOURED RACES IN THE STRUGGL. FOR LIFE.

BY CHARLES DARWIN, M.A.,

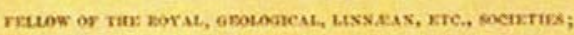

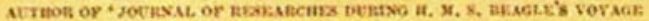

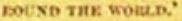

LONDON:

JOHN MURRAY, ALBEMARLE STREET.

1859.

The riplt of Trovilation is monot.

Fig. 1 On The Origin of Species by Means of Natural Selection or The Preservation of Favoured Races in the Struggle for Life by Charles Darwin. The first edition was published in 1859 in London by John Murray and this first printing of 1,250 copies sold out immediately

biomacromolecules. As this would have involved a condensation polymerisation in an aqueous solution, it has been proposed that minerals having a high surface area - such as clays - would have played a vital role in concentrating the various functional biomolecules for their subsequent polymerization. Indeed Aharon Katchalsky of the Weizmann Institute in Israel demonstrated that clays will promote the condensation polymerisation of amino acids to give protein chains when phosphates are available to provide energy to the system [4].

(ii) On the Role of Plate Tectonics on the Distribution of Species on Earth
The two main elements of the Earth's crust are oxygen and silicon. In 1859 it was assumed that the Earth's continents were fixed in place. Plate tectonics (from the Greek $\tau \dot{\varepsilon} \kappa \tau \omega v$; meaning "builder" or "mason") describes the large scale motions of the Earth's lithosphere (which consists of the Earth's crust and the rigid uppermost part of the Earth's mantle). The plate tectonics theory encompasses the older concepts of continental drift, developed during the first decades of the 20th century by Alfred Wegener, and the observation of seafloor spreading, that became understood during the 1960s. The movement of continents is one explanation that was not available to Darwin in 1859 that is able to account for the fact that the same species (or closely related species) are found on the different continents of the Earth.

(iii) On Diatoms in Ecology and in Paleolimnology

Diatoms are among the oldest species on Earth and their silica frustules are the basis of their taxonomy. The Victorians were familiar with the diatoms through use of their optical microscopes. Indeed, Darwin had commented on the beauty of their ornate silica shells. Diatoms are a valuable part of the Earth's geological fossil record and they are extremely useful as environmental indicators. The unique place of Diatoms in life on Earth is being reconsidered as their genes are being sequenced.

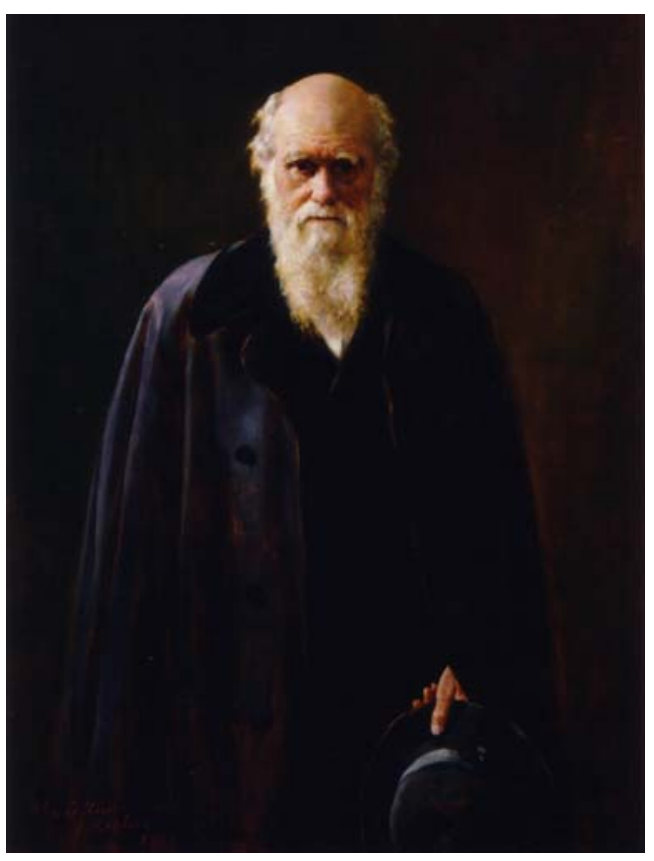

Fig. 2 The John Collier oil on canvas portrait of Charles Robert Darwin that currently hangs in the National Portrait Gallery in London (NPG 1024) 


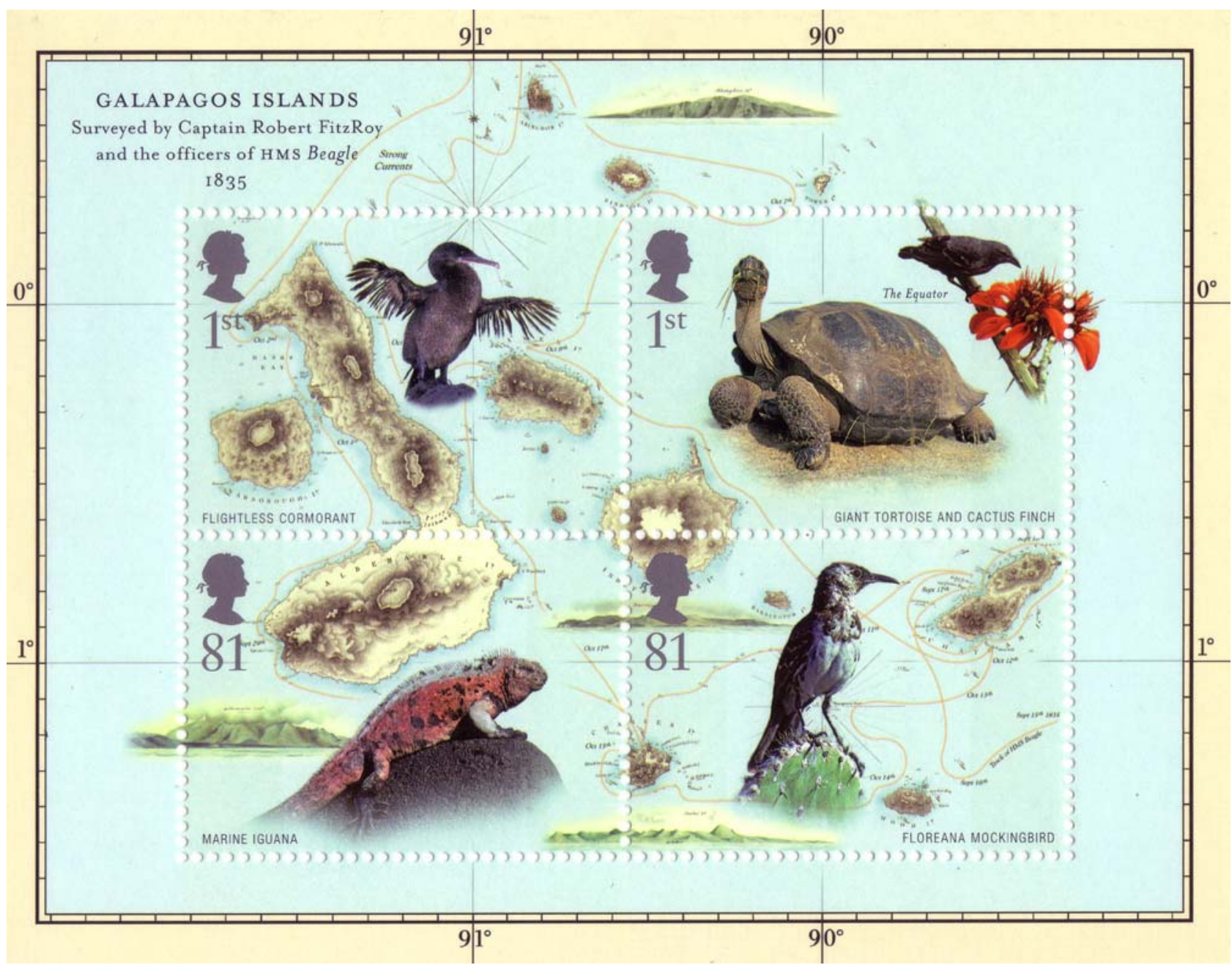

Fig. 3 The Galapagos stamp sheet

(iv) On the Use of Silicon Radioactive Isotope Dating of Rocks and Minerals

The discovery of radioactivity in 1896 by Henri Becquerel led to the radiometric dating technique (commonly called radioactive dating). This radioisotope technique has been widely applied to the rocks and other geological features of Earth and has provided us with an accurate age of the Earth itself. Thus the earliest dated solar system material has been dated to being from 4.56 billion years ago. By 4.54 billion years ago (within an uncertainty of $\pm 1 \%$ ) the Earth and the other planets in the Solar System were formed from of the materials of the Solar Nebula. There have been analyses of the silicon isotopes carried in rocks and minerals since the 1950's. There is an increasingly widespread use of silicon isotope ratios for the studies of environmental changes.

(v) On Silicon-based Information Technology and Computers
It is impossible to imagine the communications network of the Global Village without silicon technologies and glass fiber optics. The use of siliconbased computers was also vital to processing the vast amounts of data generated under the human Genome project. Thus silicon is playing an important role in storing and processing the vast amounts of genetic data that underlie the molecular mechanism of Natural Selection.

\section{Some Possible Future Contributions of Silicon to Darwin's Scientific Legacy}

Three things that Darwin could not have possibly anticipated in 1859 are: the wide range of analytical equipment and the various analytical methods that we now have in the early 21st century; that Man successfully landed on the Moon in 1969 and brought home lunar rock samples for 

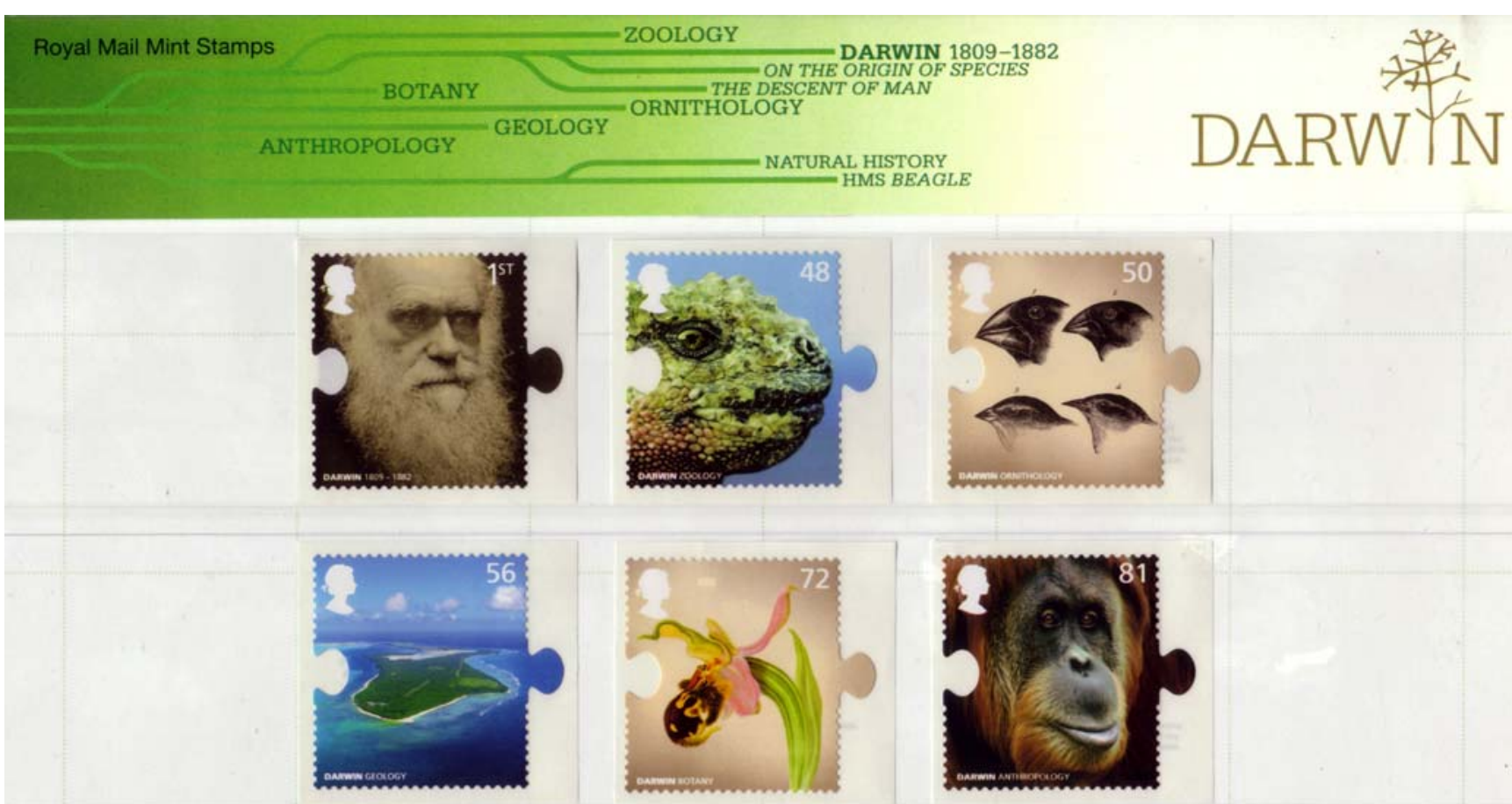

Fig. 4 The British Darwin stamp collection

analysis; and that probes have landed on Mars and Man is remotely carrying out an analysis of the composition of the Martian surface.

These developments are redefining our understanding of life in this Solar System and of the roles of the diverse species of life on Earth. I am certainly not alone in being hopeful that Earth is not the only "niche" in this Universe that can sustain carbon-based life. Furthermore, it is possible that mankind may eventually discover siliconbased life in this Universe as we continue our scientific explorations to new frontiers - as the brave young Charles Darwin did on his voyage onboard the H. M. S. Beagle [5].
Fig. 5 The Bank of England ten pound note

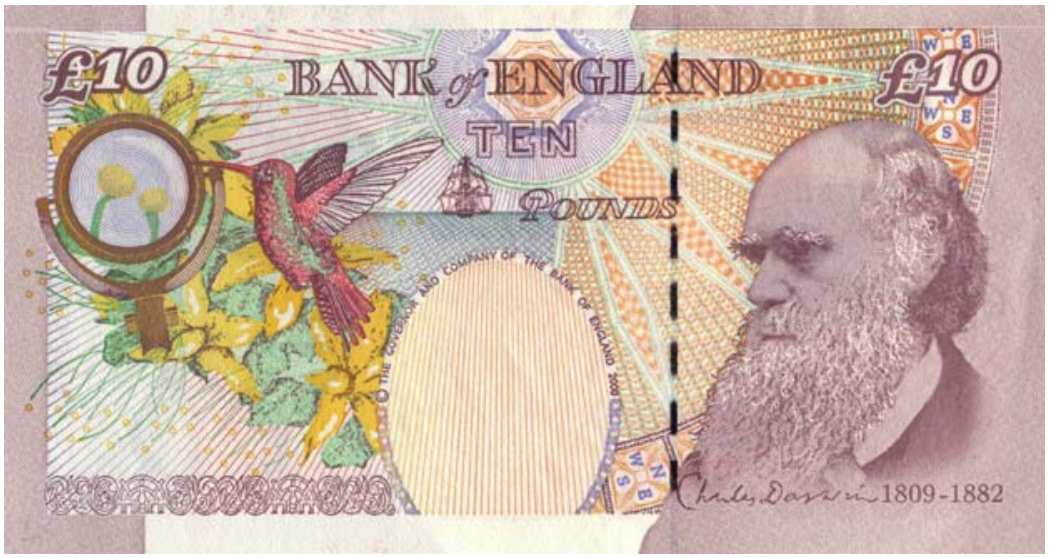




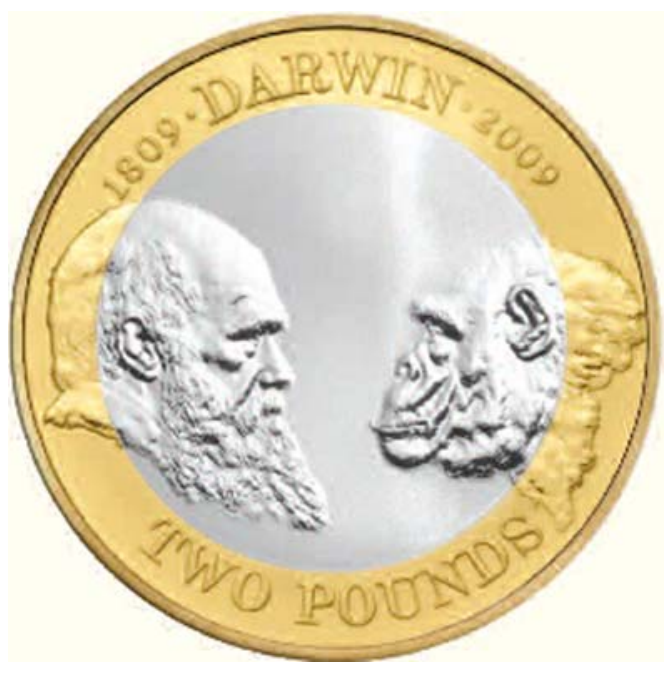

Fig. 6 The British two pound coin

\section{References}

1. Darwin C (1859) On the origin of species by means of natural selection or the preservation of favoured races in the struggle for life. John Murray, London

2. Dawkins R (2008) On the origin of species: Abridged and read by Richard Dawkins. CSA Telltapes Ltd., London

3. Mayr E (1997) This is biology: The science of the living world. Harvard University Press, Cambridge, Massachusetts

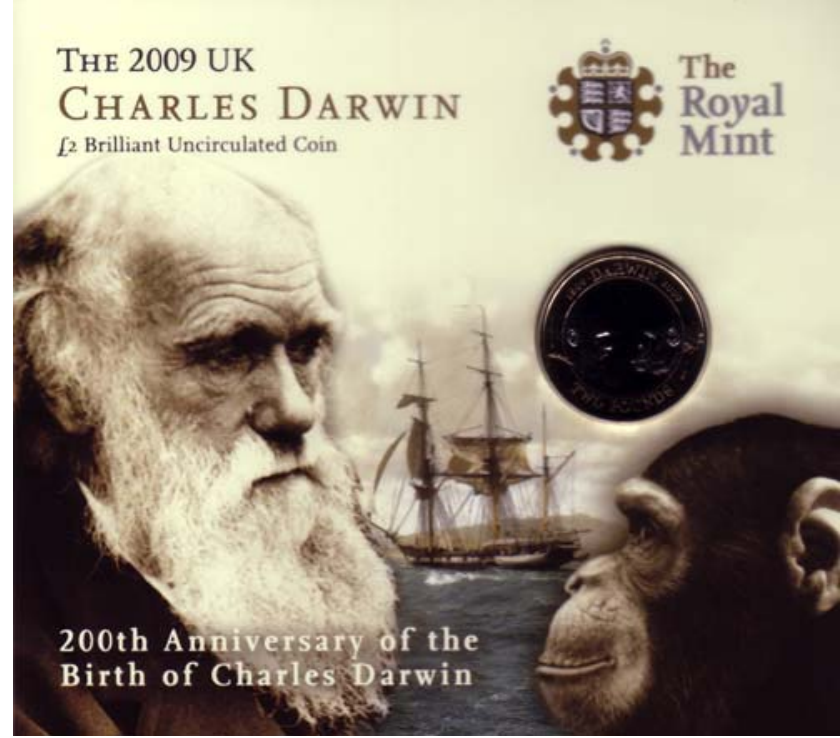

Fig. 7 The royal mint two pound Darwin anniversary coin

4. Katchalsky A (1973) Prebiotic synthesis of biopolymers on inorganic templates. Die Naturwissenschaften 60:215-220

5. Darwin CR (1839) Narrative of the surveying voyages of his majesty's ships adventure and Beagle between the years 1826 and 1836, describing their examination of the Southern Shores of South America, and the Beagle's circumnavigation of the globe. Journal and remarks. 1832-1836. Henry Colburn, London 